\title{
CORRIGENDUM
}

\section{Nocardithiocin, a novel thiopeptide antibiotic, produced by pathogenic Nocardia pseudobrasiliensis IFM 0757}

Akira Mukai, Toshio Fukai, Yasutaka Hoshino, Katsukiyo Yazawa, Ken-ichi Harada and Yuzuru Mikami

The Journal of Antibiotics (2010) 63, 99; doi:10.1038/ja.2009.129

Correction to: The Journal of Antibiotics (2009) 62, 613-619; doi:10.1038/ja.2009.90

The authors of the above article noted an error in publication of this paper in Figure 4 whereby parts $\mathrm{Ab}, \mathrm{Ac}, \mathrm{Bb}$ and $\mathrm{Bc}$ were incorrectly labelled. The correct figure is shown below.

A
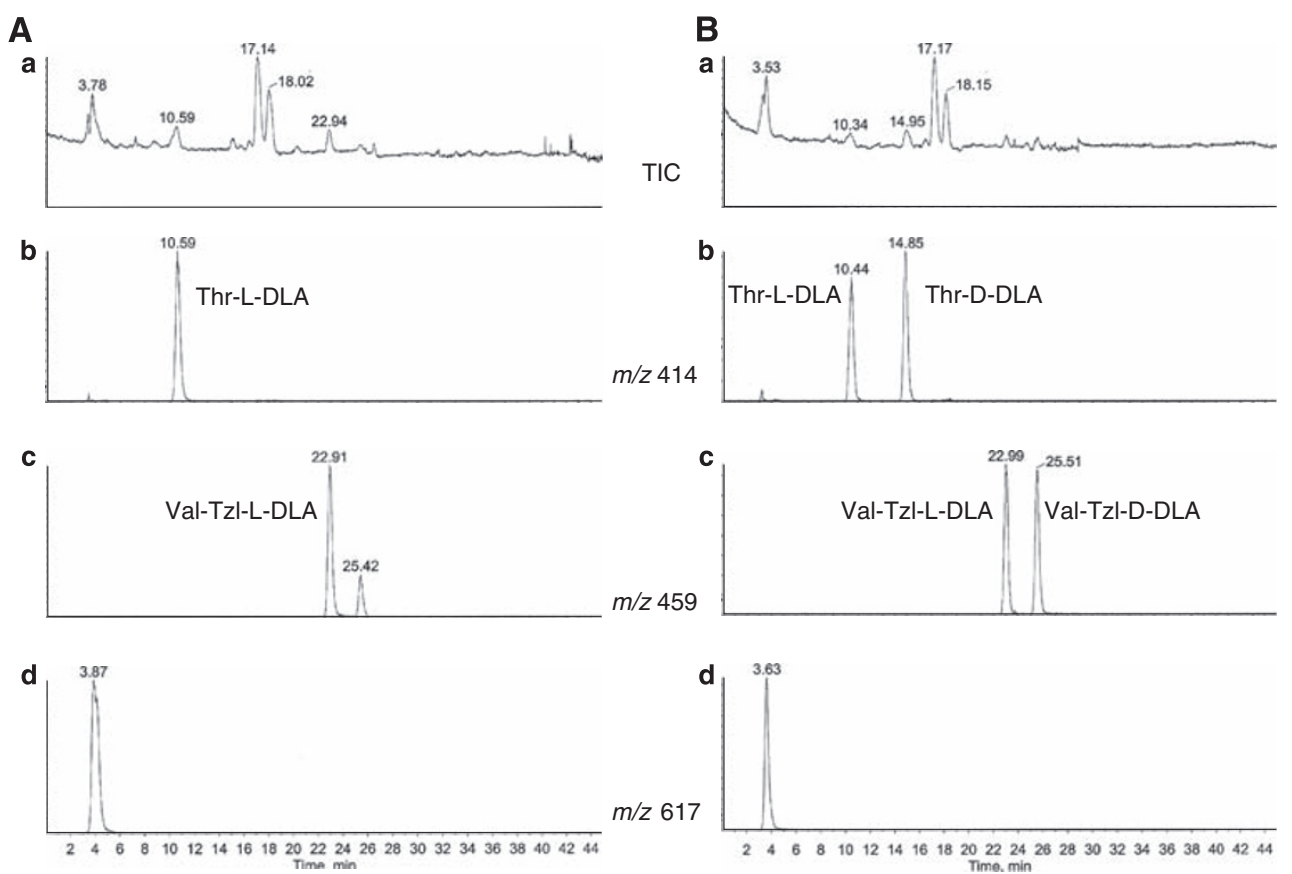

Figure $4 \mathrm{LC} / \mathrm{MS}$ data of the DLA derivatives of the reaction mixture with (A) L-FDLA and (B) L- + D-FDLA: (a) Total ion current chromatogram (TIC); (b) mass chromatogram at $\mathrm{m} / \mathrm{z} 414$; mass chromatogram at $\mathrm{m} / \mathrm{z} 459$; mass chromatogram at $\mathrm{m} / \mathrm{z} 617$. 